\title{
Studies on Acetone Powder and Purified Rhus Laccase Immobilized on Zirconium Chloride for Oxidation of Phenols
}

\author{
Rong Lu and Tetsuo Miyakoshi \\ Department of Applied Chemistry, School of Science and Technology, Meiji University, 1-1-1 Higashi-mita, Tama-ku, \\ Kawasaki-shi 214-8571, Japan \\ Correspondence should be addressed to Rong Lu, lurong@isc.meiji.ac.jp
}

Received 6 October 2011; Revised 18 January 2012; Accepted 18 January 2012

Academic Editor: Jose Miguel Palomo

Copyright ( $\odot 2012$ R. Lu and T. Miyakoshi. This is an open access article distributed under the Creative Commons Attribution License, which permits unrestricted use, distribution, and reproduction in any medium, provided the original work is properly cited.

Rhus laccase was isolated and purified from acetone powder obtained from the exudates of Chinese lacquer trees (Rhus vernicifera) from the Jianshi region, Hubei province of China. There are two blue bands appearing on CM-sephadex C-50 chromatography column, and each band corresponding to Rhus laccase 1 and 2, the former being the major constituent, and each had an average molecular weight of approximately $110 \mathrm{kDa}$. The purified and crude Rhus laccases were immobilized on zirconium chloride in ammonium chloride solution, and the kinetic properties of free and immobilized Rhus laccase, such as activity, molecular weight, optimum $\mathrm{pH}$, and thermostability, were examined. In addition, the behaviors on catalytic oxidation of phenols also were conducted.

\section{Introduction}

Rhus laccase (EC.1.10.3.2) is a copper-containing glycoprotein occurring in the exudates of lacquer trees. Yoshida [1] first discovered the enzyme in 1883. Since then, many studies of the enzyme have been conducted. However, the results obtained so far in different laboratories frequently show considerable discrepancies. For example, the molecular weight reported varies from 100 to $141 \mathrm{kDa}$ [2-4], and the properties of coppers differ considerably depending on the origin of the laccase preparations $[5,6]$.

Previously, when the Rhus laccase from Japanese lacquer trees was used to oxidize urushiol, the formation of semiquinone radicals, $\mathrm{C}-\mathrm{C}$ or $\mathrm{C}-\mathrm{O}$ coupling products, and dibenzofuran compounds were detected [7]. The enzyme laccase, whether obtained from a lacquer tree or fungus, is active in the oxidation of monophenolic compounds such as eugenol and isoeugenol [8]. The laccase-catalyzed oxidation of O-phenylenediamine [9], coniferyl alcohol [10], catechol [11], phenylpropanoid [12], and lignocatechol [13] were also demonstrated. Studies of the effects of proteins and polysaccharides in the activities of Rhus laccase showed that most proteins and polysaccharides, except laccase proteins, are not only incapable of catalyzing the oxidation of urushiol but can inhibit the activity of laccase to varying extents [14].

Recently, we immobilized Rhus laccase from acetone powder obtained from the exudates of lacquer trees grown in the Maoba region, Hubei province of China, on watersoluble chitosan and chitosan microspheres, and their properties were compared with transitional metal $\left(\mathrm{Fe}^{3+}\right)$ immobilized laccase by chelation [15]. The results showed that, compared with the free Rhus laccase, immobilized Rhus laccase displayed a lower specific activity but has a similar substrate affinity with improved stability of various parameters, such as temperature, $\mathrm{pH}$, and storage time.

Because lacquer trees are sensitive to the environmental changes of the earth, and the place of the sap production is changed in the composition of the liquid ratio and chemical structure of each component. Thus, in order to investigate the similarities and differences between the famous Chinese Maoba and Jianshi lacquer, in the present paper, we report the isolation and purification of Rhus laccases from acetone powder obtained from the exudates of lacquer trees grown in the Jianshi region, Hubei Province of China. In addition, the purified and crude Rhus laccases from acetone powder were immobilized on zirconium chloride. After the determination 
of physical and chemical properties of free and immobilized laccases was carried out, the characteristics of immobilized preparations were then compared using isoeugenol and coniferyl alcohol as substrates to compare their efficiency in catalyzing the oxidation of phenols.

\section{Materials and Methods}

\subsection{Laccase Assays}

2.1.1. Oxygen Consumption in Laccase-Catalyzed Oxidation of Catechol. Laccase was assayed by the oxygen electrode method [16]. The sample chamber $(0.6 \mathrm{~mL})$ of the oxygen electrode apparatus was washed several times with deionized water, then three times with $5 \mathrm{mM}$ catechol solution in $0.1 \mathrm{M}$ phosphate buffer solution ( $\mathrm{pH}$ 7.0: substrate solution), and filled with the substrate solution. When the dioxygen reading was stabilized, the reading scale was adjusted to $100 \%$, then $10 \mu \mathrm{L}$ Rhus laccase solution, $2 \mathrm{mg}$ purified Rhus laccase in $10 \mathrm{~mL} \mathrm{0.1} \mathrm{M} \mathrm{phosphate} \mathrm{buffer} \mathrm{solution} \mathrm{(} \mathrm{pH} 7.0$ ), was injected into the sample chamber, and the dioxygen consumption rate was recorded. At $30^{\circ} \mathrm{C}$, the concentration of dioxygen in buffer is $235 \mu \mathrm{mol} / \mathrm{L}$ due to equilibrium of dioxygen between the air and buffer. Because the volume of sample chamber is $0.6 \mathrm{~mL}$, the water in the sample chamber contains $0.141 \mu \mathrm{mol}$ of dioxygen. One unit of laccase activity was defined as the amount of laccase required to consume $0.01 \mu \mathrm{mol}$ of dioxygen $\min ^{-1}$. After $10 \mu \mathrm{L}$ of the Rhus laccase solution was injected into the system, the consumption of dioxygen $\mathrm{min}^{-1}$ was measured as percent concentration (C) of $0.141 \mu \mathrm{mol}$ dioxygen, and the laccase activity $\mathrm{g}^{-1}$ of Rhus laccase was calculated according to the following formulation:

$$
\begin{aligned}
& \text { Laccase activity (units } \min ^{-1} \mathrm{~g}^{-1} \text { ) } \\
& =\left(\frac{C}{100}\right) \times 0.141 \times\left(\frac{1}{0.01}\right) \times 5 \times 10^{5} \\
& =C \times 0.141 \times 5 \times 10^{5} \text {. }
\end{aligned}
$$

2.1.2. Laccase-Catalyzed Oxidation of p-Phenylenediamine by UV Absorbance. Deionized water was added to a solution of $0.27 \mathrm{~g}(2.5 \mathrm{mmol})$ p-phenylenediamine in $1 \mathrm{~mL} 0.2 \mathrm{~N} \mathrm{HCl}$ until the total volume was $50 \mathrm{~mL}$. Five milliliters of this solution was added to $0.1 \mathrm{M}$ phosphate buffer solution $(\mathrm{pH}$ 7.5 ) at $30^{\circ} \mathrm{C}$ so that the total volume was $50 \mathrm{~mL}$. The concentration of the resulting solution was then $5 \mathrm{mM}$. The final solution ( $3 \mathrm{~mL}$ ) was placed in a quartz cuvette, and $5 \mu \mathrm{L}$ of the purified Rhus laccase solution $\left(13.14 \mathrm{mg} \mathrm{mL}^{-1}\right)$ from Jianshi lacquer sap was added. After stirring with a microspatula, the cuvette was placed in a UV spectrophotometer, and the change in absorbance at $336 \mathrm{~nm}$ was measured as a function of time [17]. The laccase activity is defined as an increase in the absorbance of a particular absorption band at a particular wavelength per unit time ( $\mathrm{min}$ ) and unit weight of laccase (whether $\mathrm{g}$ or $\mathrm{mg}$ ). If the unit of weight is $\mathrm{g}$, then, it can be expressed as

$$
\begin{aligned}
& \text { Laccase activity }\left(\text { units } \min ^{-1} \mathrm{~g}^{-1}\right) \\
& \qquad=\frac{\operatorname{Absorbance}(\Delta A)}{[\operatorname{Time}(\Delta \min ) \times \operatorname{Amount} \text { of laccase }(\mathrm{g})]} .
\end{aligned}
$$

2.2. Preparation of Acetone Powder. The exudates (250 g) of a lacquer tree from Jianshi region, Hubei Province of China, were filtered through gauze. Then $1000 \mathrm{~mL}$ of acetone was added to the filtrate during mechanical stirring. The insoluble material (acetone powder) was washed with acetone and filtered again. This operation was repeated several times until the filtrate became clear. The resulting acetone powder was then dried at room temperature under vacuum. The yield of acetone powder was $20.6 \mathrm{~g}$. Urushiols were recovered from the combined acetone solutions by removal of the solvent at $40^{\circ} \mathrm{C}$ under vacuum.

\subsection{Isolation and Purification of Rhus Laccase from Acetone} Powder. Acetone powder (10 g) was added to $200 \mathrm{~mL}$ of $0.01 \mathrm{M}$ potassium phosphate buffer solution $(\mathrm{pH} 6.0)$. The resulting mixture was stirred mechanically for $8-12 \mathrm{~h}$ in an ice bath. The resulting solution was centrifuged and then filtered to remove any insoluble materials. The filtrate was chromatographed on a CM-Sephadex C-50 column (i.d. $40 \mathrm{~mm}$ ) prewashed with $0.01 \mathrm{M}$ phosphate buffer solution ( $\mathrm{pH}$ 6.0) using $0.01 \mathrm{M}$ phosphate buffer solution as the eluent, while being monitored with a UV detector at $280 \mathrm{~nm}$, until no adsorption was observed. The effluent was then transferred to a closed cellulose membrane dialysis tube, which was stirred in $0.01 \mathrm{M}$ phosphate buffer solution in a beaker overnight. The phosphate buffer solution contained mostly polysaccharides. The column was then eluted with $0.05 \mathrm{M}$ phosphate buffer solution ( $\mathrm{pH} \mathrm{6.0)}$ and monitored with a UV detector at $280 \mathrm{~nm}$ until no adsorption was observed. A crude peroxidase solution was obtained by dialysis of the effluent. The column was further eluted with $0.1 \mathrm{M}$ phosphate buffer solution ( $\mathrm{pH} \mathrm{6.0)}$ and monitored with a UV detector at $280 \mathrm{~nm}$ until no adsorption was observed. A crude Rhus laccase solution was obtained by dialysis of the effluent. The column was finally eluted with $0.2 \mathrm{M}$ phosphate buffer solution ( $\mathrm{pH} \mathrm{6.0)}$ and monitored with a UV detector at $280 \mathrm{~nm}$ until no adsorption was observed. A crude stellacyanin solution was obtained by dialysis of the effluent. The separation process is shown in Scheme 1.

The crude polysaccharide, peroxidase, Rhus laccase, and stellacyanin solutions were separately chromatographed on a DEAE-Sephadex A-50 column using the corresponding buffer solutions to remove yellow components. The resulting effluents containing polysaccharides, peroxidase, Rhus laccase, and stellacyanin were then chromatographed individually on a newly prepared CM-Sephadex C-50 column using $0.005 \mathrm{M}, 0.025 \mathrm{M}, 0.05 \mathrm{M}$, and $0.1 \mathrm{M}$ phosphate buffer solutions as eluents to obtain crude polysaccharide, peroxidase, Rhus laccase, and stellacyanin solutions, respectively [4]. Each effluent was finally desalted and concentrated on a CF25 


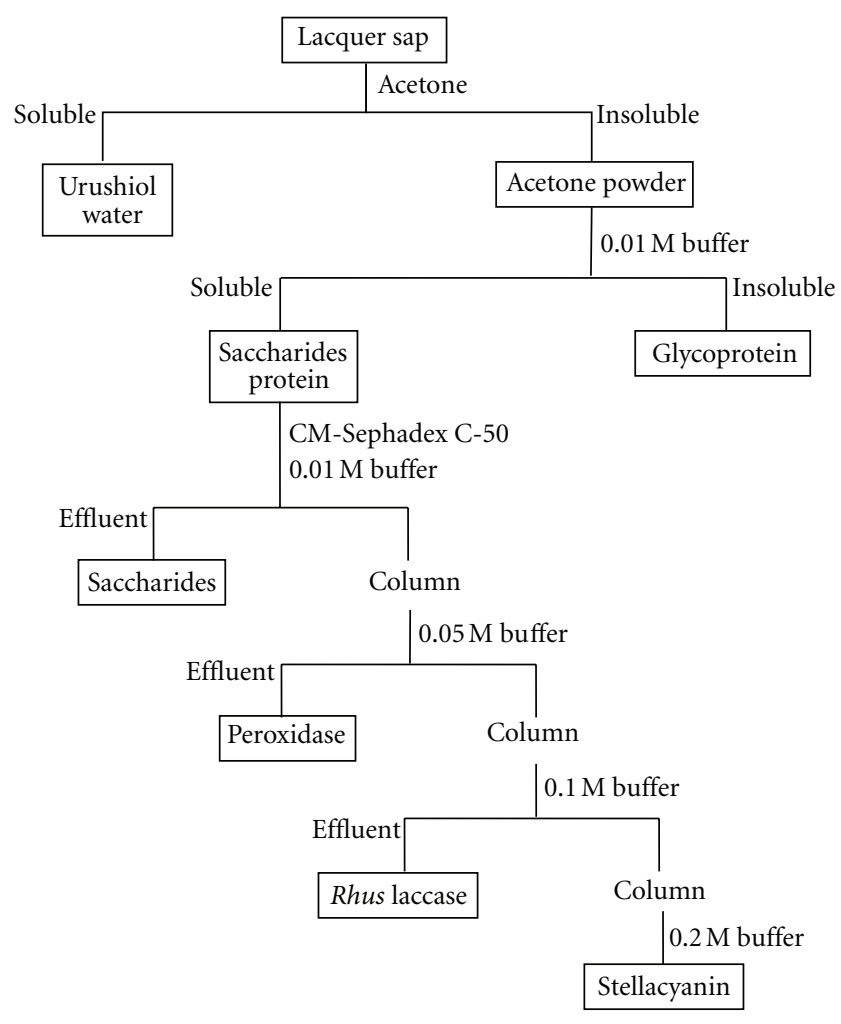

Scheme 1: Separation of lacquer sap.

membrane. The effluents were centrifuged to remove any insoluble materials and then freeze-dried.

2.4. Isolation and Purification of Rhus Laccases 1 and 2 from the Jianshi Lacquer Exudates. The resulting Rhus laccase from the Jianshi lacquer exudates was purified according to the procedure of Reinhammar [4] with a slight modification. The Rhus laccase was again chromatographed on a CMSephadex C-50 column (i.d. $40 \mathrm{~mm}$ ). There were two chromatographic bands on the column, a major and a minor band, which were eluted to obtain Rhus laccase 1 and Rhus laccase 2 , respectively.

2.4.1. Determination of Molecular Weights of Purified Rhus Laccases 1 and 2 by SDS-PAGE. The molecular weights of Rhus laccase 1 and 2 were estimated by SDS-PAGE measurement using myosin $\left(20.5 \times 10^{4}\right), \beta$-galactosidase $(11.6 \times$ $\left.10^{4}\right)$, bovine serum albumin $\left(8.2 \times 10^{4}\right)$, and ovalbumin $\left(4.7 \times 10^{4}\right)$ as the standard proteins (Prestained SDS-PAGE standards, high range, Bio-Rad's company). Because the concentration of the each standard protein is about $1.25 \mathrm{~g} / \mathrm{L}$, the concentrations of Rhus laccase 1 and 2 also were about $1.25 \mathrm{~g} / \mathrm{L}$.

2.4.2. Optimum $p H$ for Laccase Activity of Rhus Laccase 1. Deionized water was added to a solution of $0.27 \mathrm{~g}(2.5 \mathrm{mmol})$ p-phenylenediamine in $1 \mathrm{~mL} 0.2 \mathrm{~N} \mathrm{HCl}$ until the total volume was $50 \mathrm{~mL}$. To $5 \mathrm{~mL}$ of the above solution was added $0.1 \mathrm{M} \mathrm{Na}_{2} \mathrm{HPO}_{4} / \mathrm{KH}_{2} \mathrm{PO}_{4}$ buffer solution ( $\mathrm{pH} 6.0$ ) at $25^{\circ} \mathrm{C}$ so that the total volume was $50 \mathrm{~mL}$. The concentration of the resulting solution was $5 \mathrm{mM}$. The solution $(3 \mathrm{~mL})$ was then placed in a quartz cuvette, and $100 \mu \mathrm{L}$ of the Rhus laccase 1 solution $\left(0.1 \mathrm{~g} \mathrm{~mL}^{-1}\right)$ was added. After stirring with a microspatula, the cuvette was placed in a UV-spectrophotometer and the increase in the absorbance at $336 \mathrm{~nm}$ was measured as a function of time. This experiment was carried out in $0.2 \mathrm{M} \mathrm{Na}_{2} \mathrm{HPO}_{4} / \mathrm{KH}_{2} \mathrm{PO}_{4}$ buffer over $\mathrm{pH}$ range of $6.5-8.0$. In addition, the laccase activity was also assayed in $0.2 \mathrm{M}$ $\mathrm{Na}_{2} \mathrm{HPO}_{4} / \mathrm{KH}_{2} \mathrm{PO}_{4}$ buffer solution over a $\mathrm{pH}$ range of 7.0 8.5 and $\mathrm{Na}_{2} \mathrm{CO}_{3} / \mathrm{NaHCO}_{3}$ over a $\mathrm{pH}$ range of 8.5-9.5 using 2,6-dimethoxyphenol (DMP) as the substrate.

2.4.3. Thermostability of Rhus Laccase 1. The Rhus laccase 1 was kept in $0.2 \mathrm{M}$ phosphate buffer solution ( $\mathrm{pH} 6.0$ ) in a temperature range of $40-70^{\circ} \mathrm{C}$ for $10 \mathrm{~min}$. After rapid cooling, the remaining laccase activity was assayed using $p$ phenylenediamine as substrate as described in Section 2.1.2.

\subsection{Immobilization of Rhus Laccase}

2.5.1. Immobilization of Purified Rhus Laccase Using Zirconium Chloride as Carrier. To $5 \mathrm{~mL}$ of $0.65 \mathrm{M} \mathrm{HCl}$ solution was added $0.62 \mathrm{~g}$ of $\mathrm{ZrCl}_{4}$. The resulting mixture was neutralized with $2 \mathrm{M} \mathrm{NH}_{4} \mathrm{OH}$ solution under a hood and placed in an ice bath. A dropwise solution of $6.9 \mathrm{mg}$ purified Rhus laccase in $1.0 \mathrm{~mL}$ deionized water was added within $2 \mathrm{~h}$ with stirring. The immobilized Rhus laccase was filtered and kept in the refrigerator. 
2.5.2. Immobilization of Acetone Powder Containing Rhus Laccase Using Zirconium Chloride as Carrier. To $5 \mathrm{~mL}$ of $0.65 \mathrm{M} \mathrm{HCl}$ solution, $0.62 \mathrm{~g}$ of $\mathrm{ZrCl}_{4}$ was added. The resulting mixture was neutralized with $2 \mathrm{M} \mathrm{NH}_{4} \mathrm{OH}$ solution under a hood and placed in an ice bath. A solution of $1 \mathrm{~g}$ acetone powder in $10 \mathrm{~mL}$ deionized water was added drop-wise over $2 \mathrm{~h}$ with stirring. The immobilized Rhus laccase was filtered and kept in the refrigerator.

2.6. Kinetics of Immobilized Rhus Laccase and Acetone PowderCatalyzed Oxidation of Phenols. The activity of immobilized laccases was measured spectrophotometrically at $30^{\circ} \mathrm{C}$ using p-phenylenediamine as a substrate; $0.0146 \mathrm{~g}(0.135 \mathrm{mmol}) \mathrm{p}$ phenylenediamine was dissolved in $100 \mathrm{~mL} 0.02 \mathrm{M} \mathrm{pH} 6.8$ phosphate buffer. The final solution $(3 \mathrm{~mL})$ was placed in a quartz cuvette, and the appropriate amount of immobilized laccase was added. After stirring with a microspatula, the cuvette was placed in a UV spectrophotometer and the change in absorbance at $336 \mathrm{~nm}$ was measured as a function of time.

2.7. Catalysis of Phenols. Isoeugenol $(0.5 \mathrm{~g})$ in $10 \mathrm{~mL}$ acetone was added to phosphate buffer $(0.1 \mathrm{~mol} / \mathrm{L}, \mathrm{pH} 7.5,10 \mathrm{~mL})$. An appropriate amount of each enzyme (see Tables 2 and 3 ) was added to this substrate solution and was stirred at $30^{\circ} \mathrm{C}$ for $24 \mathrm{~h}$ with aeration. The disappearance of substrate and yields of products was monitored by thin layer chromatography at specific intervals. The solvent of the remaining solution was removed under reduced pressure by evaporation, and the resulting residue was extracted using ethyl acetate, washed with saturated sodium chloride solution, dehydrated and dried over anhydrous sodium sulfate, and then concentrated by evaporation to yield a yellow liquid. This yellow liquid was eluted and purified on silica gel using $3: 2(\mathrm{v} / \mathrm{v})$ hexane/ethyl acetate as eluting agent. The products of oxidation were analyzed by gas chromatography (GC) and gas chromatography/mass spectrometry (GCMS). Oxidation of coniferyl alcohol as catalyzed by the enzymes was similarly performed and purified on silica gel using $1: 1(\mathrm{v} / \mathrm{v})$ hexane/ethyl acetate as the eluting agent.

\section{Results and Discussion}

3.1. Major Constituents of Jianshi Lacquer Exudates. The exudates of a Chinese lacquer tree (Rhus vernicifera) from the Jianshi region, Hubei Province, China, contained about 8.2\% of acetone-insoluble components, that is, the acetone powder contained polysaccharides, peroxidase, Rhus laccases, and stellacyanin. The remaining acetone-soluble material contained mostly urushiols, although the constituents of the acetone-soluble fraction were not investigated further. The acetone powder was systematically analyzed according to the procedure of Reinhammar [4].

It contained polysaccharides, Rhus laccases, peroxidase, and stellacyanin at $25 \%, 2.1 \%, 0.13 \%$, and $0.32 \%$, respectively, as summarized in Table 1 . The nature of the remaining components is not known.
TABLE 1: Yield of the constituents of acetone powder from exudates of Chinese lacquer tree grown in Jain-Shi, Hubei province, China.

\begin{tabular}{|c|c|c|}
\hline \multirow{2}{*}{$\begin{array}{l}\text { Constituents of } \\
\text { acetone powder }\end{array}$} & \multicolumn{2}{|c|}{ Yield from $10 \mathrm{~g}$ of acetone powder } \\
\hline & Yield in weight $(\mathrm{g})$ & $\begin{array}{c}\text { Yield in } \\
\text { percentage }(\%)\end{array}$ \\
\hline Polysaccharides & 2.5 & 25.0 \\
\hline Rhus laccase & 0.21 & 2.1 \\
\hline Peroxidase & 0.013 & 0.13 \\
\hline Stellacyanin & 0.032 & 0.32 \\
\hline
\end{tabular}

3.2. Purification and Characterization of Rhus Laccase 1 and 2. The Rhus laccases were purified according to the procedure of Reinhammar [4] with a slight modification. When chromatographed on a CM-Sephadex C-50 column, the Rhus laccase was found to contain two chromatographic bands, a major and a minor band, which were denoted laccase 1 and 2, respectively. The purified Rhus laccases 1 and 2 were shown to be homogeneous based on polyacrylamide $(5 \%)$ gel electrophoresis in $\mathrm{pH} 4.5$ buffer solution as previously described [7]. In addition, they each gave only one band on sodium dodecyl sulfate polyacrylamide gel electrophoresis according to the standard method.

The migrations of Rhus laccases 1 and 2 were identical by gel filtration and SDS-PAGE experiments, and the molecular mass of the enzymes was estimated to be $110 \mathrm{kDa}$ (Figure 1). This value is consistent with the reported data for the Rhus laccase from Japanese urushi exudates calculated from the copper content. Isoelectric focusing of Rhus laccase 1 was conducted on PAGE plates at a $\mathrm{pH}$ range of 3-10 using pI markers set (IEF-MIX 3.5-9.3, Sigma Chemical Co.) as the $\mathrm{pI}$ indicator. The result showed a major band at $\mathrm{pH} 8.6$ and a very minor band at $\mathrm{pH}$ 7.9. A certain asymmetry in the activity curve of Rhus laccase was observed in the column isoelectric focusing. Thus, the aforementioned results indicated that Rhus laccase 1 had microheterogeneity.

The laccase activity of Rhus laccase 1 was determined to be $2.1 \times 10^{4} \mathrm{~min}^{-1} \mathrm{~g}^{-1}$ using $p$-phenylenediamine as substrate at $\mathrm{pH}$ 7.0. The activity of Rhus laccase 2 was determined to be approximately $90 \%$ of the Rhus laccase 1 .

3.3. Optimum $p H$ and Thermostability of Crude Rhus Laccase in Acetone Powder. The optimum $\mathrm{pH}$ of crude Rhus laccase in acetone powder ( $1 \mathrm{~g}$ acetone powder in $20 \mathrm{~mL}$ $\mathrm{pH} 6.86$ phosphate buffer) was dependent on the nature of the substrate: $\mathrm{pH} 7.0$ for $p$-phenylenediamine and $\mathrm{pH}$ 8.5 for 2, 6-dimethoxyphenol (DMP) at $37^{\circ} \mathrm{C}$ using $0.2 \mathrm{M}$ $\mathrm{Na}_{2} \mathrm{HPHO}_{4} / \mathrm{NaH}_{2} \mathrm{PO}_{4}$ solution over $\mathrm{pH}$ range of $6.0-8.0$ and $\mathrm{Na}_{2} \mathrm{CO}_{3} / \mathrm{NaHCO}_{3}$ solution over $\mathrm{pH}$ range of 7.0-9.5, as shown in Figure 2. Because of a mixture of Rhus laccase 1 and 2, and effect of lacquer polysaccharides or/and other isoenzymes [14], the optimum $\mathrm{pH}$ of crude $(\mathrm{pH} 7.0)$ and purified (pH 7.5, Figure 4) Rhus laccases is slightly difference.

Because the crude Rhus laccase in acetone powder has the highest activity in $\mathrm{pH} 7.0$ at $37^{\circ} \mathrm{C}$, the thermostability of them was then examined in $0.2 \mathrm{M} \mathrm{Na}_{2} \mathrm{HPHO}_{4} / \mathrm{NaH}_{2} \mathrm{PO}_{4}$ 


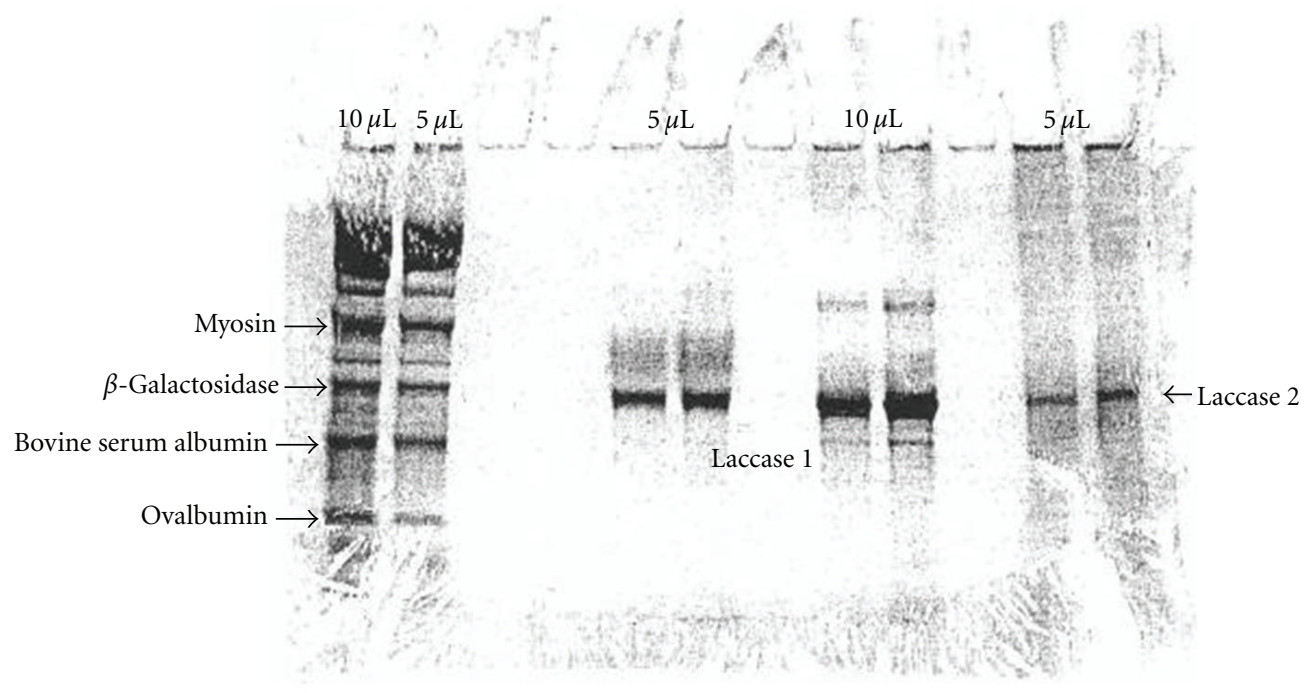

FIGURE 1: SDS-PAGE results of Rhus laccase and standard proteins.

TABLE 2: Yield of oxidation of isoeugenol by Rhus laccase.

\begin{tabular}{lccccc}
\hline \multirow{2}{*}{ Entry } & Yield $(\mathrm{g})$ & \multicolumn{3}{c}{ Ratio of compounds (\%) } \\
& & Isoeugenol & Compound 1 & Compound 2 & Compound 3 \\
\hline 1 & 0.43 & 54.2 & 24.0 & 22.3 & 3.7 \\
2 & 0.39 & 22.9 & 47.8 & 25.1 & 5.7 \\
3 & 0.49 & 7.5 & 58.2 & 30.8 & 9.1 \\
4 & 0.36 & 0.6 & 53.7 & & 14.8 \\
\hline
\end{tabular}

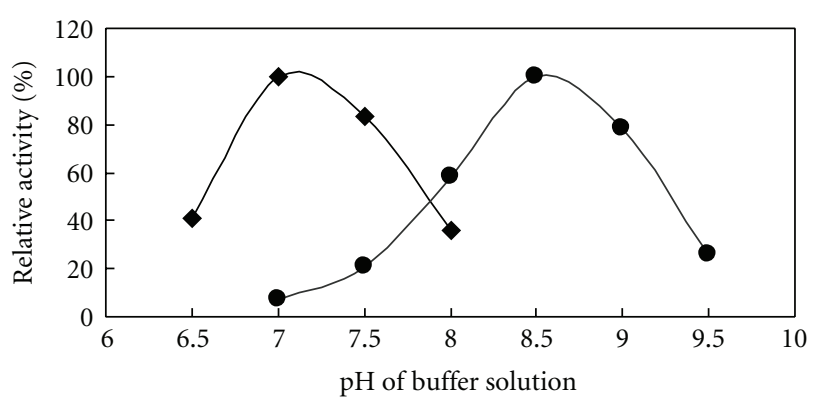

Figure 2: Optimum pH for the crude Rhus laccase at $37^{\circ} \mathrm{C}$ using p-phenylenediamine and 2.6-dimethyphenol as substrates: $\mathbf{\square}: p$ phenylenediamine; $\bullet$ : 2.6-dimethyphenol.

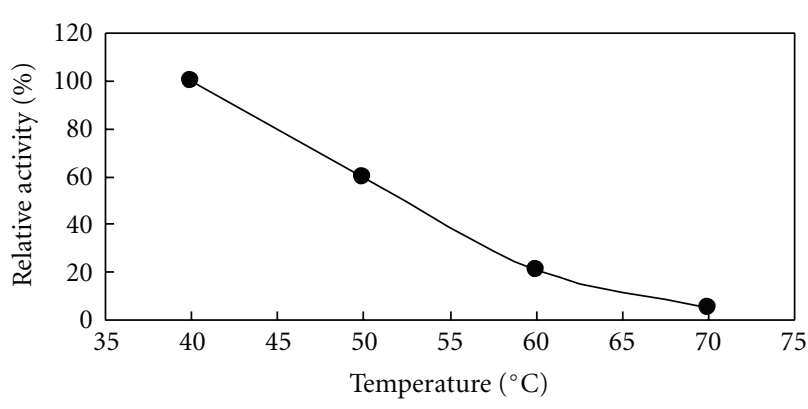

Figure 3: Thermostability of the crude Rhus laccase in $0.2 \mathrm{M}$ phosphate buffer at $\mathrm{pH} 7.0$ in the temperature range of $40-70^{\circ} \mathrm{C}$.
pH 7.0 buffer solution over the temperature range of 40$70^{\circ} \mathrm{C}$ for 10 minutes, as shown in Figure 3. The crude Rhus laccase was heat-resistant vicinity $40^{\circ} \mathrm{C}$ and almost completely deactivated at $70^{\circ} \mathrm{C}$.

3.4. Assay of Rhus Laccase Activity. The laccase activity of the purified Rhus laccase was determined by the oxygen electrode method using catechol, isoeugenol, and other substrates and by UV spectrophotometry with $p$-phenylenediamine as a substrate. The laccase activity of purified Rhus laccase 1 was determined to be $3.5 \times 10^{2}$ units $\min ^{-1} \mathrm{~g}^{-1}$ using catechol as substrate. Because laccase-catalyzed oxidation of catechol proceeds according to the following reaction equation:

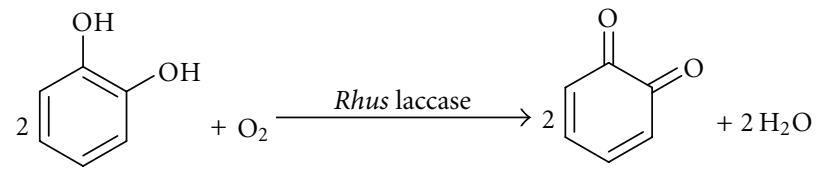

When catechol is used as substrate for assay of the laccase activity, one unit of laccase activity corresponded to the amount of laccase required to reduce $0.01 \mu \mathrm{mol}$ of dioxygen to $0.02 \mu \mathrm{mol}$ of water $\mathrm{min}^{-1}$. It also corresponds to the amount of laccase required to oxidize $0.02 \mu \mathrm{mol}$ catechol to $0.02 \mu \mathrm{mol} o$-quinone $\mathrm{min}^{-1}$. When $p$-phenylenediamine was used as the substrate for assay of laccase activity, the change 
TABLE 3: Yield of oxidation of coniferyl alcohol by Rhus laccase.

\begin{tabular}{|c|c|c|c|c|c|c|}
\hline \multirow{2}{*}{ Entry } & \multirow{2}{*}{ Repeat (times) } & \multirow{2}{*}{ Yield (g) } & \multicolumn{4}{|c|}{ Ratio of compounds (\%) } \\
\hline & & & Coniferyl alcohol & Compound 4 & Compound 5 & Compound 6 \\
\hline 1 & 1 & 0.36 & 0 & 60.0 & 26.1 & 13.9 \\
\hline 2 & 1 & 0.31 & 0 & 56.3 & 29.6 & 14.1 \\
\hline 3 & 2 & 0.33 & 24.9 & 42.8 & 21.1 & 11.2 \\
\hline
\end{tabular}

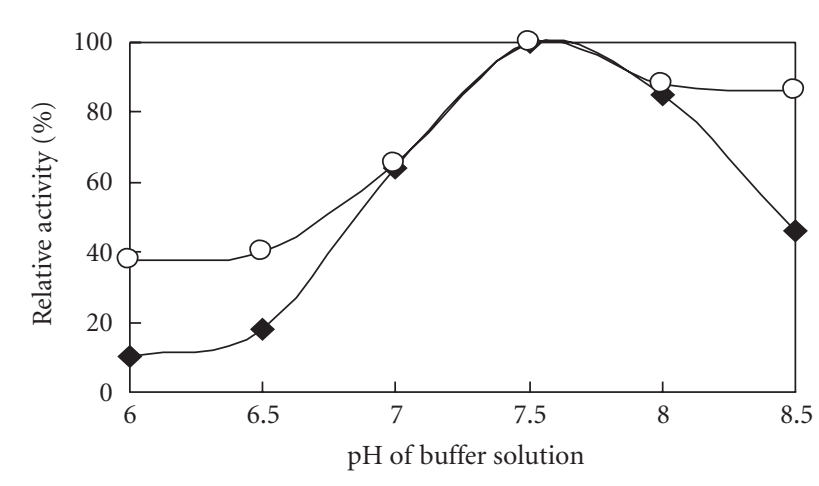

FIgURE 4: Relationship between $\mathrm{pH}$ and activity of Rhus laccase, $\bigcirc$ : immobilized Rhus laccase; $\downarrow$ : free purified Rhus laccase.

in absorbance at $336 \mathrm{~nm}$ was measured as a function of time. The laccase activity is defined as an increase in absorbance of a particular absorption band at particular wavelength with unit time ( $\mathrm{min}$ ) and unit weight of laccase (whether g or $\mathrm{mg}$ ) [18]. If the unit of weight is the gram, then it can be expressed in units $\min ^{-1} \mathrm{~g}^{-1}$, and the laccase activity of purified Rhus laccase was determined to be $5.5 \times 10^{2}$ units $\min ^{-1} \mathrm{~g}^{-1}$. When isoeugenol was used as the substrate, the laccase activity was determined to be $1.7 \times 10^{2}$ units $\min ^{-1} \mathrm{~g}^{-1}$. The difference in activity data may be due to the different water solubilities of substrates and enzyme selectivity.

\subsection{Immobilization of Purified and Crude Rhus Laccase from Acetone Powder}

3.5.1. Optimum $p H$ for Immobilized Laccase. The optimum $\mathrm{pH}$ for immobilized laccase activity was examined using $p$-phenylenediamine as the substrate at $37^{\circ} \mathrm{C}$. The result showed that the optimum $\mathrm{pH}$ for immobilized laccase was 7.5. At $\mathrm{pH}$ values $6.0,6.5$, and 8.5 , the activity of immobilized laccase is more stable and higher than that of the free purified laccase and showed almost the same activity with the free purified laccase at the $\mathrm{pH} 7.0,7.5$, and 8.0 (Figure 4). It can be considered that because of the interaction between the $\mathrm{ZrCl}_{4}$ carrier and laccase, the immobilized laccase formed a stable structure that is less susceptible to the environment, and the activity units calculated with per mg of protein are higher than in free laccase.

3.5.2. Thermostability of Immobilized Laccase. The thermostability of the immobilized laccase was determined using $p$ phenylenediamine as the substrate at $\mathrm{pH}$ 7.5. The result showed that the optimum temperature for immobilized

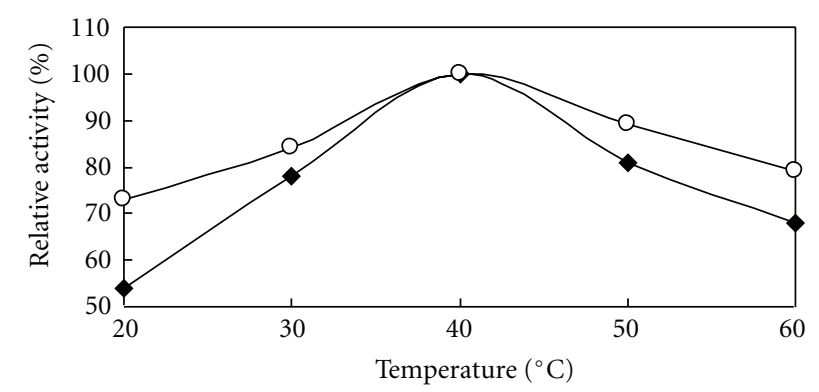

FIGURE 5: Relationship between temperature and activity of Rhus laccase, $\bigcirc$ : immobilized Rhus laccase; $\diamond$ : free purified Rhus laccase.

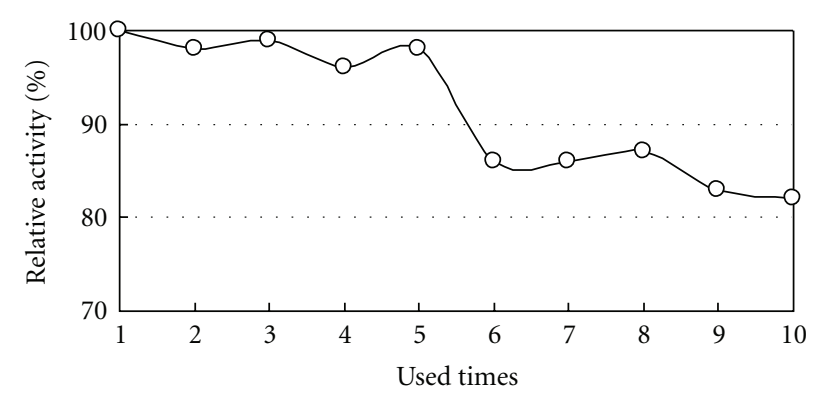

FIGURE 6: Relationship between repeated used times and activity of Rhus laccase.

laccase is $40^{\circ} \mathrm{C}$. In the temperatures at 20,3050 , and $60^{\circ} \mathrm{C}$, the activity of immobilized laccase was more stable and higher than that of the free laccase and showed almost the same activity with the free purified laccase at $40^{\circ} \mathrm{C}$ (Figure 5). This phenomenon also can be considered due to the stable structure of immobilized laccase.

3.5.3. Effects of Repeated Use of Immobilized Laccase. The effect of repeated use on the immobilized laccase activity was examined using $p$-phenylenediamine as the substrate in phosphate buffer ( $\mathrm{pH} 7.5)$ at $37^{\circ} \mathrm{C}$ for 10 minutes and is shown in Figure 6. The relative activity slowly decreased during repeated use, although after 10 uses, it retained over $80 \%$ of its initial activity, indicating good potential repeated use efficiency.

3.6. Catalytic Oxidation of Isoeugenol. The purified, crude, immobilized purified, and immobilized crude Rhus laccases were used to oxidize $0.5 \mathrm{~g}$ of each isoeugenol monomers in $30^{\circ} \mathrm{C}$. After reacting for $24 \mathrm{~h}$, the solvent was removed by evaporation and extracted with ethyl acetate and washed 


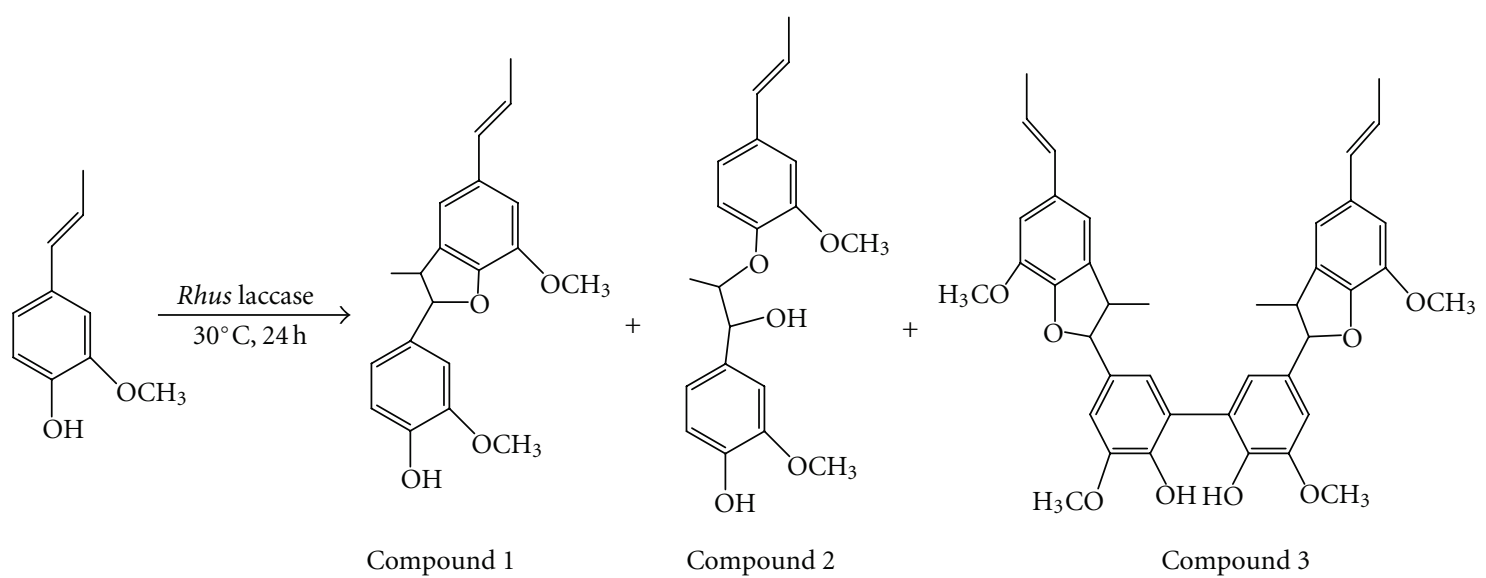

Scheme 2: Oxidation of isoeugenol by Rhus laccase.

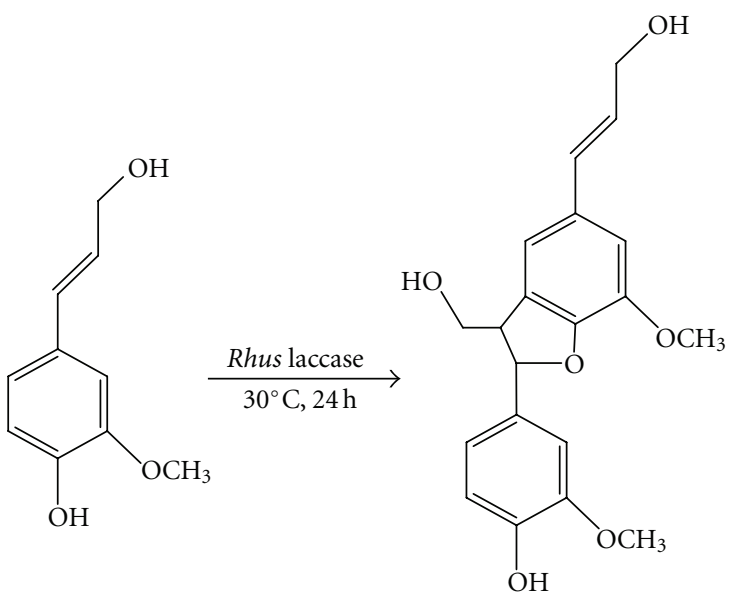

Compound 4<smiles>COc1cc(C2OCC3C(c4ccc(O)c(OC)c4)OCC23)ccc1O</smiles>

Compound 5<smiles>COc1cc(C(O)C(CO)Oc2ccc(/C=C/CO)cc2OC)ccc1O</smiles>

Compound 6

Scheme 3: Oxidation of coniferyl alcohol by Rhus laccase.

with saturated $\mathrm{NaCl}$ solution. The ethyl acetate extract was dehydrated using anhydrous sodium sulfate. After removing the solvent, a yellow syrupy was obtained. The yellow syrupy product was purified by column chromatography on silica gel (hexane: ethyl acetate $=3: 2$ ). The overall yields are $0.43,0.39,0.49$, and $0.36 \mathrm{~g}$ respectively, as summarized in Table 2. In Table 2, entries 1, 2, 3, and 4 are the purified, immobilized purified, crude, and immobilized crude Rhus laccases, respectively. The reaction solution for purified Rhus laccase (entries 1 and 2) was $10 \mathrm{~mL} 0.1 \mathrm{M}$ phosphate buffer ( $\mathrm{pH}$ 7.5) mixed with $10 \mathrm{~mL}$ acetone and for crude Rhus laccase (entries 3 and 4 ) was $10 \mathrm{~mL}$ distilled water mixed with $10 \mathrm{~mL}$ acetone.

It was found that in the same reaction condition, the ratio of the products is compound $1>$ compound $2>$ compound 3 . The immobilized enzyme (entries 2 and 4 ) catalyzed more product than the free enzyme (entries 1 and 3 ), and these results may be due to a stable active site structure of the immobilized enzyme that supports zirconium chloride. In addition, a higher yield was obtained from the crude enzyme catalytic reaction (entries 3 and 4 ) than the purified enzyme (entries 1 and 2), and this can be considered due to a salt sensitivity of Rhus laccase, decreasing the yield of the reaction products in the phosphate buffer. The reaction image is shown in Scheme 2.

3.7. Catalytic Oxidation of Coniferyl Alcohol. The free crude and immobilized crude Rhus laccase from the acetone powder was used to oxidize $0.5 \mathrm{~g}$ of each coniferyl alcohol monomer in a mixed solution $(10 \mathrm{~mL}$ distilled water $+10 \mathrm{~mL}$ acetone) at $30^{\circ} \mathrm{C}$. After reacting for $24 \mathrm{~h}$, the solvent was removed by evaporation and extracted with ethyl acetate and washed with saturated $\mathrm{NaCl}$ solution. The ethyl acetate extract was dehydrated using anhydrous sodium sulfate. After removing the solvent, a light yellow syrupy was obtained. The light yellow syrupy product was purified by column chromatography on silica gel (hexane:ethyl acetate $=1: 1$ ). The ratio of reaction products is summarized in Table 3, and the reaction image is shown in Scheme 3. 
In the same reaction condition, the ratio of the products was compound $4>$ compound $5>$ compound 6 . The yield percentage of each compound catalyzed by the free or immobilized enzyme (entries 1 and 2) was almost the same. Because phosphate buffer was not used in this reaction, no salt sensitivity affected the activity of the free enzyme. In addition, the free enzyme cannot be used again, while the second use of the immobilized enzyme still yielded about $75 \%$ coniferyl alcohol dimers (entry 3 ).

\section{Conclusion}

The Rhus laccase in the acetone powder from exudates of Chinese lacquer tree grown in Jainshi, Hubei Province, China, was examined. The crude laccase of the acetone powder was dissolved with phosphate buffer and the laccase purified by a Sephadex column was immobilized with zirconium chloride. The properties of free and immobilized laccase were investigated using $p$-phenylenediamine, isoeugenol, and coniferyl alcohol as substrates. The molecular weight of laccase was estimated to be $110 \mathrm{kDa}$ according to the SDSPAGE method. The activity of the Rhus laccase was determined to be $2.1 \times 10^{4} \mathrm{~min}^{-1} \mathrm{~g}^{-1}$ using $p$-phenylenediamine as a substrate at $\mathrm{pH}$ 7.0. After immobilization with zirconium chloride by chelation, the immobilized laccase retained over $80 \%$ of its initial activity after catalyzing $p$-phenylenediamine 10 times. In the catalytic reaction of isoeugenol to produce isoeugenol dimer, the immobilized enzyme produced more products than the free enzyme, and this may be because of the stable active site structure of the immobilized enzyme that supports zirconium chloride. In the catalytic reaction with coniferyl alcohol to produce dimers, although almost the same yield was observed in the catalyzation by the free or immobilized enzyme, the immobilized enzyme could be used repeatly and about 75\% coniferyl alcohol dimer was obtained in the second use as a catalyst.

To summarize, Rhus laccase immobilized by chelation using zirconium chloride has many excellent properties. It showed stable activity in organic solvents and water, at various $\mathrm{pHs}$, and reaction temperatures. Rhus laccase immobilized with zirconium chloride is an economical enzyme due to its repeated usability and stable activity.

\section{Acknowledgments}

This work was partly supported by the Academic Frontier Project for Private Universities, a matching fund subsidy from MEXT (2007-2011), Meiji University.

\section{References}

[1] H. Yoshida, "LXIII.-Chemistry of lacquer (Urushi). Part I. Communication from the Chemical Society of Tokio," Journal of the Chemical Society, Transactions, vol. 43, pp. 472-486, 1883.

[2] T. Nakamura, "Purification and physico-chemical properties of laccase," Biochimica et Biophysica Acta, vol. 30, no. 1, pp. 44-52, 1958.
[3] T. Omura, "Studies on laccases of lacquer trees," The Journal of Biochemistry, vol. 50, no. 3, pp. 264-272, 1961.

[4] B. Reinhammar, "Purification and properties of laccase and stellacyanin from Rhus vernicifera," Biochimica et Biophysica Acta, vol. 205, no. 1, pp. 35-47, 1970.

[5] T. Nakamura, A. Ikai, and Y. Ogura, "The Nature of the Copper in Rhus vernicifera vernicifera Laccase," The Journal of Biochemistry, vol. 57, no. 6, pp. 808-811, 1965.

[6] E. I. Solomon, M. J. Baldwin, and M. D. Lowery, "Electronic structures of active sites in copper proteins: contributions to reactivity," Chemical Reviews, vol. 92, no. 4, pp. 521-542, 1992.

[7] J. Kumanotani, "Enzyme catalyzed durable and authentic oriental lacquer: a natural microgel-printable coating by polysaccharide-glycoprotein-phenolic lipid complexes," Progress in Organic Coatings, vol. 34, no. 1-4, pp. 135-146, 1997.

[8] T. Sakurai, "Laccase activates monophenols, eugenol and isoeugenol," Journal of Pharmacobio-Dynamics, vol. 14, p. S114, 1991.

[9] D. F. Zhan, Y. M. Du, and B. G. Qian, "Oxidation product of $O$-phenylenediamine catalysed by Toxicodendron vernicifera laccase," Chemistry and Industry of Forest Products, vol. 11, pp. 13-16, 1991.

[10] T. Shiba, L. Xiao, T. Miyakoshi, and C. L. Chen, "Oxidation of isoeugenol and coniferyl alcohol catalyzed by laccases isolated from Rhus vernicifera Stokes and Pycnoporus coccineus," Journal of Molecular Catalysis B, vol. 10, no. 6, pp. 605-615, 2000.

[11] N. Aktas, A. Tanyolac, J. Mole, and B. Cataly, "Kinetics of laccase-catalyzed oxidative polymerization of catechol," Biological Sciences, vol. 22, no. 1-2, pp. 61-69, 2003.

[12] Y. Wan, R. Lu, K. Akiyama, T. Miyakoshi, and Y. Du, "Enzymatic synthesis of bioactive compounds by Rhus vernicifera laccase from Chinese, Rhus vernicifera," Science in China B, vol. 50, no. 2, pp. 179-182, 2007.

[13] T. Yoshida, R. Lu, S. Han et al., "Laccase-catalyzed polymerization of lignocatechol and affinity on proteins of resulting polymers," Journal of Polymer Science A, vol. 47, no. 3, pp. 824$832,2009$.

[14] Y. Y. Wan, R. Lu, K. Akiyama et al., "Effects of lacquer polysaccharides, glycoproteins and isoenzymes on the activity of free and immobilised laccase from Rhus vernicifera," International Journal of Biological Macromolecules, vol. 47, no. 1, pp. 76-81, 2010.

[15] Y. Y. Wan, Y. M. Du, X. W Shi et al., "Immobilization and characterization of laccase from Chinese Rhus vernicifera on modified chitosan," Process Biochemistry, vol. 41, no. 6, pp. 1378-1382, 2006.

[16] T. Miyakoshi, K. Nagase, and T. Yoshida, Progress of Lacquer Chemistry, IPC Publisher, Tokyo, Japan, 1999.

[17] D. F. Zhan, Y. M. Du, and B. G. Qian, "Study of immobilized laccase and its properties," Chemistry and Industry of Forest Products, vol. 11, pp. 111-116, 1991.

[18] T. Terada, K. Oda, H. Oyabu, and T. Asami, Urushi-the Science and Practice, Rikou Publisher, Tokyo, Japan, 1999. 

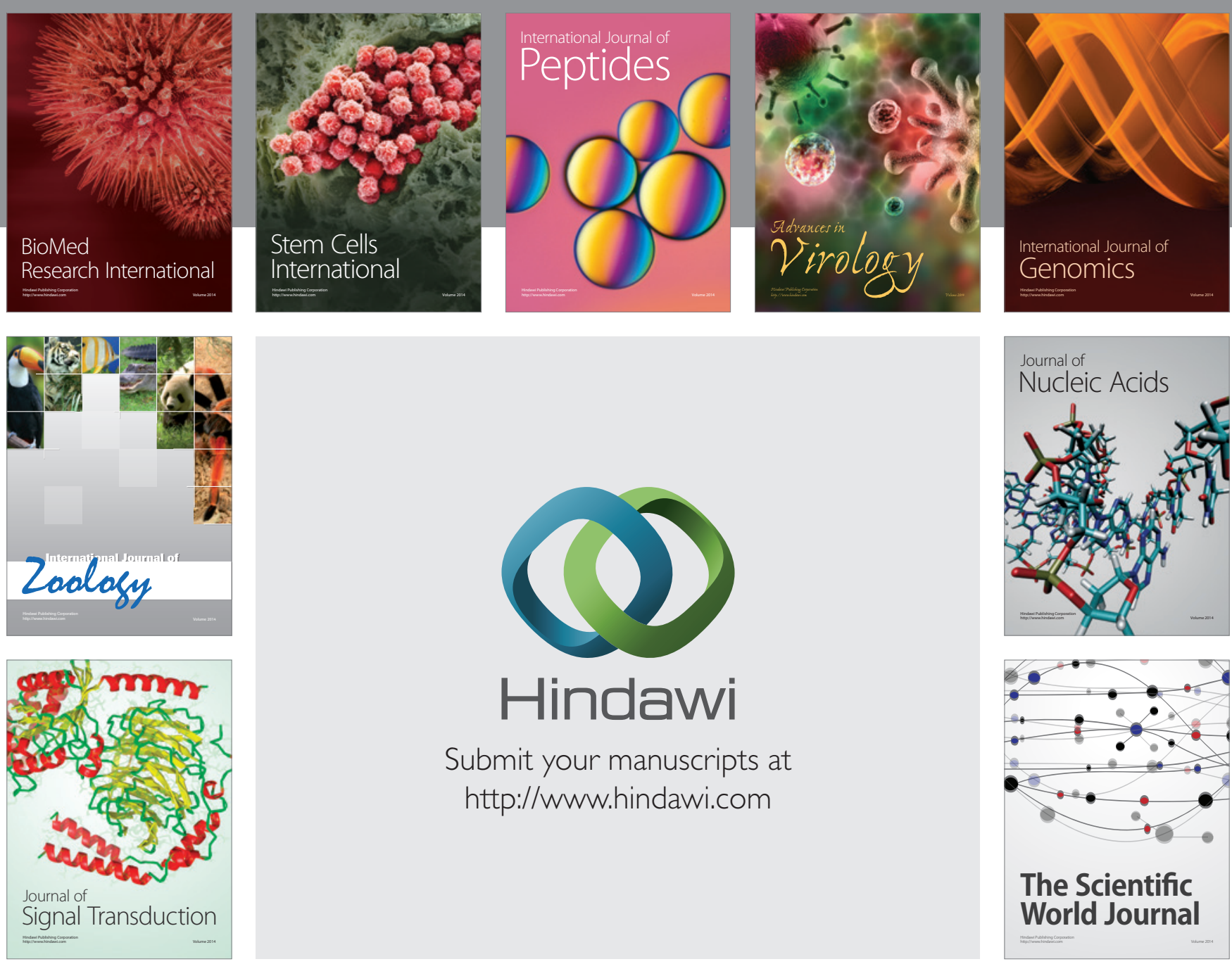

Submit your manuscripts at

http://www.hindawi.com
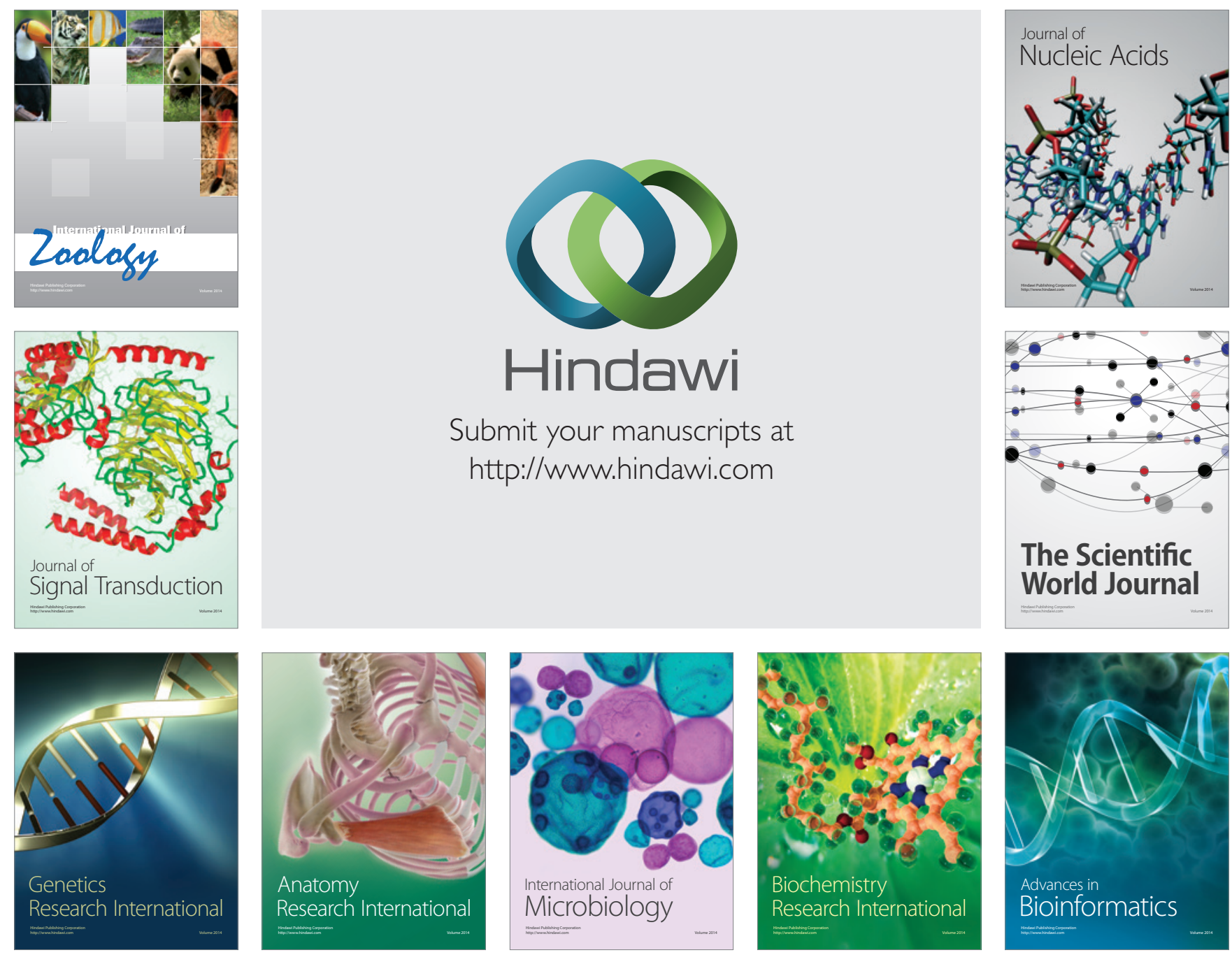

The Scientific World Journal
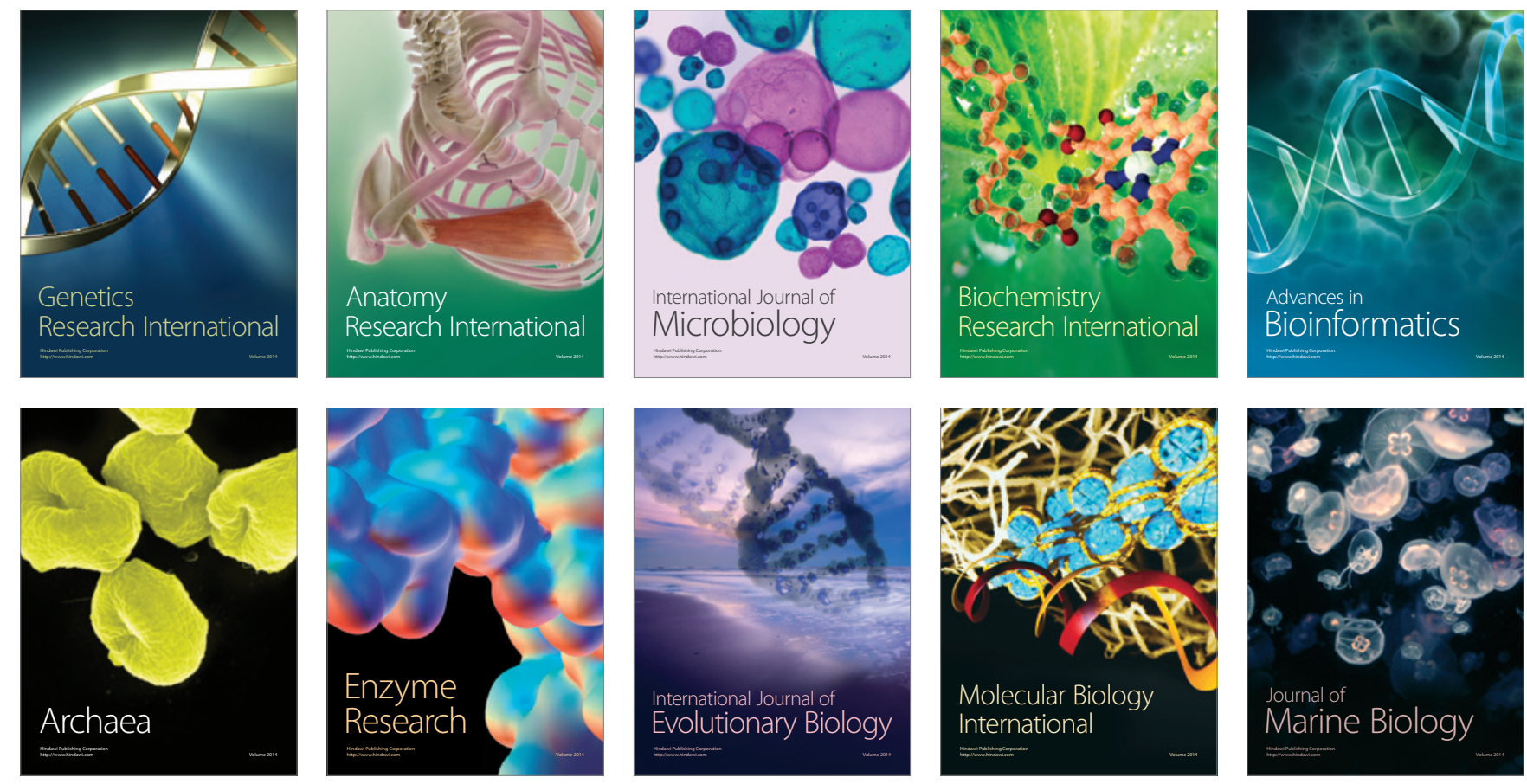